\title{
Reading the Epigraph-Figuration in Sergei Slonimsky's Master and Margarita
}

\author{
T. A. Dunne \\ The College of Saint Rose, \\ 432, Western Avenue, Albany, N. Y., 12203, USA
}

For citation: Dunne, Timothy. "Reading the Epigraph-Figuration in Sergei Slonimsky's Master and Margarita”. Vestnik of Saint Petersburg University. Arts 10, no. 2 (2020): 192-209. https://doi.org/10.21638/spbu15.2020.201

The research here brings under scrutiny an essential compositional element found in Sergei Slonimsky's 1972 operatic score, Master and Margarita. At issue is the "Epigraph-Figuration" - a 14-note chromatic melody presented on the score's frontispiece and found in a myriad of variation throughout the 3-hour chamber opera. Teasingly abstract in its aspect, not limited to any one particular dramatic role, and in reflexive correspondence with the Goethe quote commencing Bulgakov's famous novel, the Epigraph-Figuration has inspired compelling exegesis and speculation. Exactly because the attraction of extra-musical hermeneutics is so strong for scholars of Bulgakov's Master and Margarita, Slonimsky's melodic figuration has lacked an objective examination sufficient enough to explain the significance of its many kaleidoscopic incarnations. This is exemplified, but not limited to, the compelling hypotheses of multi-disciplinary scholar Siglund Bruhn who sees the figuration as a representation of spiritual "opening" - symbolically significant as she places it in the dynamic context of the Soviet history of cultural thaw and cultural repression well known to Slonimsky and his peers and colleagues. But the present author will arrive at an alternate orientation, aided in no small part by a brief paradigmatic analysis of the actual, empirical presence of the Epigraph-Figuration in ten selected score excerpts. With the recent passing of Slonimsky, the music world and contemporary Russian culture has lost not only a fabulously brilliant and dedicated composer, but a courageous civic figure who tirelessly dedicated his life to the musical development of others with unflinching moral certitude and uncompromising creative integrity. The present author, and former student of Slonimsky, arrives at an alternate conclusion, discovering in the Epigraph-Figuration a robust illustration of one of the composer's most salient aesthetic principles - affinity for the Subject and care for its right to individual growth - demonstrated in his unique treatment of each of its multiple, morphological iterations.

(c) Санкт-Петербургский государственный университет, 2020 
Keywords: Sergei Slonimsky, Mikhail Bulgakov, Johann Wolfgang von Goethe, epigraph-figuration, Siglund Bruhn, expanding wedge contour, paradigm analysis, permutation.

To The Blessed Memory of My Teacher, Sergei Mikhailovich Slonimsky

In his article on Bulgakov's Master and Margarita, "Beyond Parody: The Goethe Connection", Andrew Barratt has observed that "No discussion of good and evil in Goethe and Bulgakov would be complete without some reference to what has remained one of the thorniest problems of all - Bulgakov's choice of epigraph" [1, p. 118].

- ...Who are you, then?

- I am part of that power which eternally wills evil and eternally works good.

Wolfgang von Goethe [2, p. 1].

Beginning with the title ultimately chosen for his novel ${ }^{1}$, an apparent nod to the operatic repertoire cherished by Bulgakov, this epigraph becomes the second referent in a long line of intertextual signification which busily threads its way through to the story's end, some 400 pages later. Barratt remarks that despite there being a surplus of "some of the most inventive (although sometimes most confusing) interpretations" of this epigraph, there is a dominating tendency in Bulgakov criticism to apply overly reductive interpretations which threaten the epigraph's "rhetorical force and semantic density". He argues that the Goethe / Bulgakov epigraph ideally functions as "an interpretive exercise" for the reader and affords them a provisional map by which to traverse the novel's complexly over-populated, multiplying, and hyper-referential storylines [see: 1, p. 119]. Any tool, it would seem, that could help the reader work through the ingenious, but structurally and philosophically problematic Master and Margarita should be a welcomed advantage. With its plot super-saturated with drama, pathos, outrageous humor, time travel, horror, contemporary farce, and a plethora of additionally distracting cultural semiosis, an orientation device procured from Goethe's epic poem - one of the most revered works of European literary culture - could hardly be elicited by Bulgakov as some gratuitous afterthought. And if the epigraph functions then as an "exercise", we might ask, what exactly are the literary muscles being toned, and which intellectual posture being assumed?

1 "The Great Chancellor", "Satan", "The Black Magician", were some of the working titles ultimately abandoned in favor of "Master and Margarita". Of particular interest to English translators and editors of Bulgakov's novel the following should be considered: An obsessive fan and aficionado of opera himself, Mikhail Bulgakov was present at no fewer than 43 performances of Gounod's Faust. Consider just some of the titles to opera's iconic pairs: Tristan und Isolde, Ruslan and Ludmila, Dido and Aeneas, Roméo and Juliette, Peleas and Melisandre, Orfeo ed Euridice, Porgy and Bess, etc. Could the choice of the title "Master and Margarita" be anything other than a corresponding nod to this legacy of tragic love? His Master is, after all, otherwise nameless. This hero is, for all intents and purposes, simply "Master" - just as "Margarita" is the proper (first) name of Bulgakov's heroine. These appellations clearly and equally function as proper names in the novel and a translator's habitual reaction, to automatically tack on a definite article where one is absent in the Russian, i. e. The Master, may want to be seriously questioned in the future. 


\section{Epigraph, Exercise, and Figuration}

The Oxford Dictionary of Literary Terms defines epigraph rather plainly as "a quotation or motto placed at the beginning of a book, chapter, or poem as an indication of its theme" [3]. History suggests that the practice of placing these quotes or mottos at the beginning of literary works may have begun earlier than the $18^{\text {th }}$ century, but then rushed into vogue with the industrial age. Enabled by an appreciably wider geographic distribution and the growth of a readers market for fiction, the epigraph could cleverly add to the appeal of a new work as it drew comparison to, and "piggy-backed" upon, the vaunted legacy of the older work being referenced - often a masterpiece itself. And like books of fiction, products of inventive fantasy and a fluid intellect, printed musical scores can likewise present themselves as the observable repository of cultural legacy and creative potential.

The score to Sergei Slonimsky's 1972 chamber opera Master and Margarita is no exception here. Printed directly onto its frontispiece is a riddle-clue in the form of a notational epigraph - a graphic object illustrating a melodic strand extracted from the score's Epilogue ${ }^{2}$, and placed just below it on a separate system, an excerpt from rehearsal 136 also from Part III. The sound-mass emerging out of the lower half of the frontispiece complex, resembling a final roll of thunder, quotes the choir / organ's fully chromatic cluster dissolving into silence in the opera's last measures. Like a curtain banishing the light of the preceding drama it cloaks this tragic work with a palpable sense of unease as the opera draws to a close. The arpeggiated sound-mass, or cluster ${ }^{3}$ represents a singular occurrence, a powerful, discreet musical event in the opera whose fitting placement on the closing page leaves no doubt that the composer intended to highlight the "philosophical part of the novel"4 in his libretto. I refer to it as a figuration because as essential as this musical element becomes to the opera, it retains the kind of neutrality which a motif can not abide by. Motifs generally take on other motifs, wrestle with them, and reformulate those materials into novel structures along some grander teleological plane. Figurations, on the other hand, while able to resemble a motif in isolation, do not engage in the kind of transgressive and subliminal moves between "parts and the whole" that characterize motifs, but stubbornly remain surface elements - readily perceptible as they are dependable.

But it is the discreet melodic "figuration" ${ }^{5}$ printed just above it on the frontispiece which represents the most recognizable and singular melodic component within Slonimsky's Master and Margarita. And while it may be argued that the choice of frontispiece arrived on the score as the unremarkable result of an editor's whim or preordained publishing convention, the indisputable significance of the 14-note melodic strand, revealed over the course of the 3-hour opera, confirms the primacy of its function and value - its appropriate place of prominence at the scores opening page. Not only is it a (self

2 Rehearsal mark 118.

${ }^{3}$ See: [4, p. 399]. Out of countless versions of tone-clusters available to the $20^{\text {th }}$ Century composer of atonality the kind of cluster in question here meets the last (my italicized) criteria of "internal intervallic construction (microtonal, 1/2 step, whole tone, mixed intervals)". Appropriately, for the biblical themes in the Master and Margarita libretto, one of the Russian terms in fashionable use during the writing of Slonimsky's opera included "thunder".

${ }^{4}$ From my interview with Slonimsky 13.11.2019 (All quotes from this interview are translated by the author).

5 "The [figuration] has its own history in the music of Slonimsky.. <... The first of its prototype appeared in the fugal theme of the Sonata for Violin Solo, then in the guise of a twelve-tone theme in 'Dialogues' then found its way in 'Gilgamesh' and 'Monologues'” [5, p. 82]. 


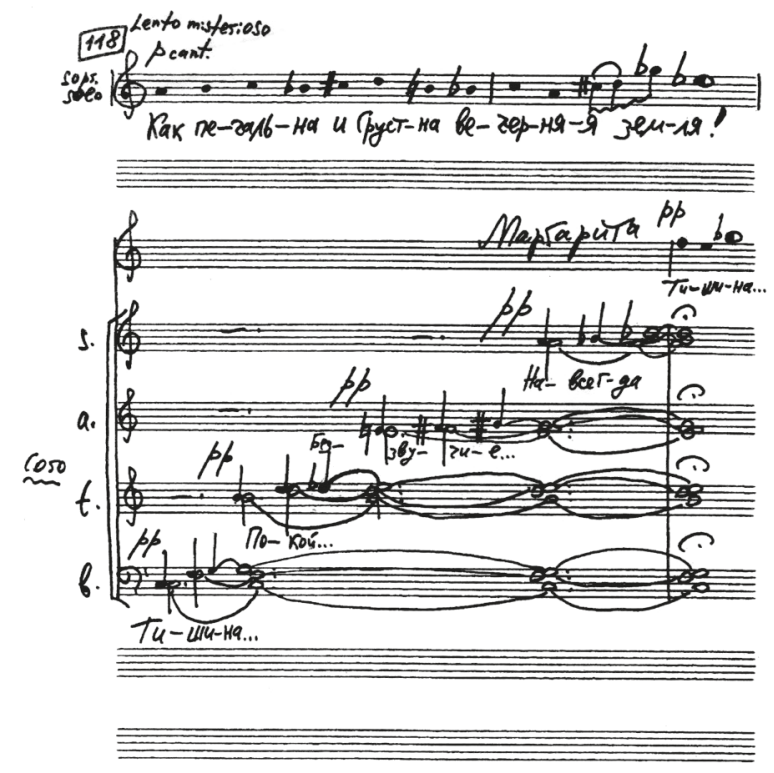

Fig. 1. S. Slonimsky. Master and Margarita. Frontispiece of the conductor's score [I, p. 1]

referential) "quote" and a "motto" or "theme", but it precisely articulates Andrew Barratt's notion of the epigraph as an "exercise" (fig. 1).

The significance of this Epigraph-Figuration then is the subject of the present research. Of particular interest is the question of whether an extra-musical, semantic value can be gleaned from an analysis of its numerous iterations and ubiquitous presence in the opera. It is worth considering that before a musical score - a highly specialized form of printed text, and a physical, visual, factual object - magically transforms into the sonic ephemera we call music and before the laws of acoustical causality are launched into sonic existence and the irretrievable molecules of vibrating air meet the tympanum of our ears, the musical score presents its readers / interpreters (the conductor, the performing musicians, the curious musicologist or student, etc.) with a plethora of semiotic value. This is because musical scores, like the fanciful editions of some literary works, are frequently packed with a superabundance of visual cues (sometimes clues) and disparate sign systems thrown together as a single, readable language: in addition to the graphic symbols indicating pitch and duration, relative loudness and proper articulation, they are notoriously replete with esoteric markings, numerical codes, a jumble of foreign languages, practical hints on a good performance, footnotes, dedications, memorials, messages, copyright warnings, cataloging data, editors remarks, written introductions, portraits, frontispieces, and sometimes even epigraphs... The score format then, taken as a self-contained trace record, "a single mechanism" [6, p.xii], offers a faithful illustration of Yuri Lotman's concept of the semiosphere $^{6}$ - a provisional, asymmetrical and dynamic nexus where disparate cultural

${ }^{6}$ In the 1980s Lotman worked out his theory of his neologism semiosphere, describing it as a cultural space and comparing it to a virtual "museum hall where exhibits from different periods are on display, along with descriptions in known and unknown languages, and instructions for decoding them; there are also the 
codes collide and propagate. This is the case particularly when a score can be approached not only for its essential utilitarian value (i. e. an "instruction manual" for getting the musicians to faithfully reconstruct the composer's sound designs beginning with point $A$ and ending with point $\mathrm{Z}$ ), but as a multi-dimensional, hermeneutic source for theoretical and musicological examination.

\section{Leitmotif? Leitthema?}

In the years since Milka's observations were made, surprisingly little research has explored the question of the "important role" of this figuration. But in her 1991 monograph, Composer Sergei Slonimsky [7], Marina Rizareva explored how in Slonimsky's ballet Icarus (1971), the figuration she calls a "leitthema" utilized the melodic strand in an inconspicuously programmatic way, citing how with each appearance its discreet, sharply contoured form reflects the well-known and tragic endeavor of Icarus's ascent. In the ballet, it seems, the expanding chromatic melody behaves with a predictable climbing motion - an unambiguous quality not easily lost on any listener. As Rizareva approaches the analysis of the "leitthema" (figuration) in Master and Margarita she draws together the themes of immortality of both Jeshua and Master with their intervallic half-step connections, and then further between the torturous conscience shared by Master and Pilate and made manifest in the inverse (Major $7^{\text {th }}$ intervals). Significantly, she is careful to characterize the musical-dramatic development in the opera, melodically speaking, as unique to each role, and does not impose a one-dimensional, reductionist interpretation on the "leitthema" per se. Another analysis appearing in the Journal of Music and Meaning in 2007 [8] not only addressed this recurrent musical element of Slonimsky's, but went as far as to suggest that in his Master and Margarita it enjoys the unique status of "the opera's principal motif" . Siglund Bruhn's "Jesus and Satan in Moscow: Three Late-20th-Century Operas on Bulgakov's Novel" ambitiously tracks and compares the diverse compositional origins, poetics, and score analyses of Bulgakov's novel as interpreted by composers Sergei Slonimsky, Rainer Kunad, and York Höller, and reveals the mind and moral prerogatives of an innovative musicologist thinking globally. In regard to the Epigraph-Figuration, Bruhn draws our attention to an excerpt which appears late into Part III - the tolling of chimes which announce the culmination of Satan's Ball scene. Significantly, she designates this as the "principle motif" while maintaining that it nevertheless "does not concern any aspects of the individual dramatic scene unfolding at the moment [it] is heard" [8] - a point that should be worthy of our curiosity. Without pursuing that idea further she then proceeds to simply describe some of its constitutive formal aspects (fig. 2).

According to her illustration (see: fig. 3), Bruhn presents this melodic contour as a symmetrically generated, clearly expanding, stepwise movement out of a central starting pitch. For her it describes a movement towards: "expansion or growth [and] seems to contain a message that does not concern any aspects of the individual scene unfolding

explanations composed by the museum staff, plans for tours and rules for the behavior of the visitors..." [6, p. 126].

7 Bruhn describes the Epigraph-Figuration as a continual presence in the opera "which pervades all three acts and is taken up by many characters and instruments". See: [8]. Through a particularly contemporary, humanizing lens of Western-European Christian morality, her refreshing intertextual analysis was very appreciatively received by Slonimsky himself. 


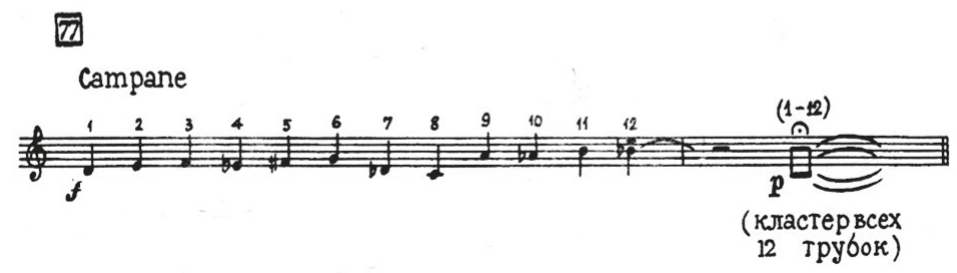

Fig. 2. S. Slonimsky. Master and Margarita. Part III [I, p. 316, Rehearsal no. 77]

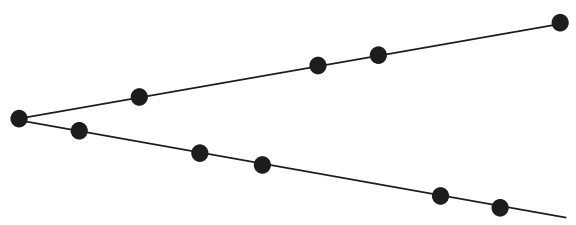

Fig. 3. Bruhn's paradigmatic rendering of a symmetrically expanding wedge contour [8, p. 12]

at the moment when the motif is heard, but the rather work as whole. One might read the figure as liberation from narrowness, a widening of the inner view, perhaps even as a continuous growth of understanding" [8, p. 14]. In the present article I prefer to refer to this figure as the "Epigraph-Figuration", as I not only concur with Bruhn in her assertion that the figure's status is one of primary importance in the opera, but that importance is analogous to Bulgakov's Goethe epigraph. As such, I have tried to follow Andrew Barratt's admonition not to lose sight of the "rhetorical force and semantic density" of the epigraph (here Epigraph-Figuration) by being too myopically fixed on a single meaning. While the study here is of a relatively cursory nature I intend to outline what is essentially going on with the hyper-variable syntax of this Epigraph-Figuration.

To this end, it is instructive to clarify the difference between the present author's and Bruhn's usage of the term "motif". We both see it as a building block upon which a greater logical consistency helps to develop the work's overall significance. It is hard to disagree with Bruhn when she argues that "the motif's signification thus resembles the quality that Slonimsky and his librettists seem to have in mind in their emphasis on the 'true and eternal love' toward which so many of the central characters develop." [8, p. 12]. A discussion about musical semantics should first be built upon an objective and simple accounting of the musical subject in question, "on its own specifically musical terms, with the construction of a complex subjectivity and its relationship to the whole [work]" [9, p. 104] In other words, "what is said is inseparable from how it is said" [9, p. 104]. I believe that Bruhn's conclusions are limited by the reliance on the idealized wedge illustration 
presented below. Its "incomplete, elemental nature" [10], characterizing a motif, never develops nor is subsumed into a greater compositional plan, structurally speaking. Instead the Epigraph-Figuration morphology is charted by a serial, but non-linear, representation at each of its multitudinous instances. Its occurrences in the opera always follow discreet, phrase length durations - manageable, on a receptive level, for an average listener. But the cross-layered and unifying property of this "motif" cy important for Bruhn, is determined not by an over-arching compositional design, but by the libretto's storyline and themes.

\section{Wedge Contours. Paradigmatic Analysis}

For clarification, I propose to first offer a definition of the chromatically expanding contour, and then by further abstracting the examples on a graph I hope to impart to the reader an optically clear view of the diverse forms of variation with which the Epigraph-Figuration empirically manifest themselves throughout the opera. A chromatically expanding wedge contour then is:

a melodic object originating and sustained through a single voice which spreads out chromatically and progressively from an initial, central tone in a systematic alternation of upward and downward pitch trajectories. ${ }^{9}$

Bruhn's model certainly corresponds to the conditions of the definition above ${ }^{10}$, and while Bruhn's rendering does not specify the size of intervallic divergence (there is neither musical staff, nor a numerical graph by which to quantify the divergence), the illustration presents the sequence of expanding points at a consistent angle in agreement with my definition above. The problem I see with Bruhn's analysis is that this figuration, playing as it does one of the most significant roles in the thematicism of Master and Margarita, is only an idealized version of the Epigraph-Figuration. In Part I of the opera alone there are approximately one hundred appearances of the Epigraph-Figuration and very few indeed possess the kind of simplified rendering provided in her article. I therefore have chosen ten excerpts for the actual diversity of forms they possess. To paraphrase not the poet, but the poet-scientist Goethe I propose that in order to truly grasp the nature of the Epigraph-Figuration we need to pay better attention to the "expansion and contraction,

${ }^{8}$ See also: [11, p. 82]. "[Motives] fundamental property involves their cross-level connections, repetitions, variations and interweaving with other motives within the text creating its unique poetics". (Translation by the author).

9 The "expanding wedge contour" has emerged conspicuously in some of the $20^{\text {th }}$ Century's most celebrated early 20 modernist works including Stravinsky's The Rite of Spring and Bartok's Music for Strings, Percussion and Celesta. But it has been particularly favored with the Post-War avant-garde. Penderecki's Threnody makes prolific, if very obscured, use of it and for composers Harrison Birtwistle and György Ligeti whose work, like Slonimsky's, has frequently featured a preponderance of both monodic and polyphonic writing it functions as a destabilizing, entropy inducing, and centrifugal strategy. One of the more interesting questions of perception regarding the expanding wedge contour is - at what point of its bifurcating and horizontal processes does the listener begin to hear not one line, but two or more?

${ }^{10}$ For a concise, but exemplary supplemental study of how these expanding wedge contours function, and which became an identifiable hallmark of British composer Harrison Birtwistle's (especially early) music [see: 12, p. 23]. Cross suggests that these "activation of planes" derive from painter Paul Klee's theories espoused in the artist's Pedagogical Sketchbook, first published in 1925. An essential characteristic of expanding chromatic wedge patterns is their dependence on a symmetrical construction "beginning from a single point" (pitch). 


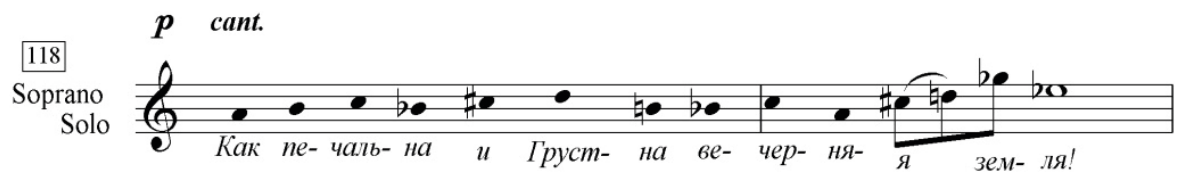

Fig. 4. Epigraph-Figuration from the frontispiece of the score

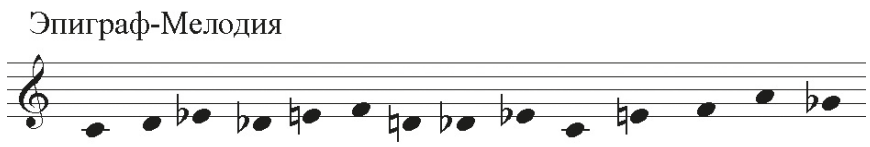

Fig. 5. Step One - Transposition to C4

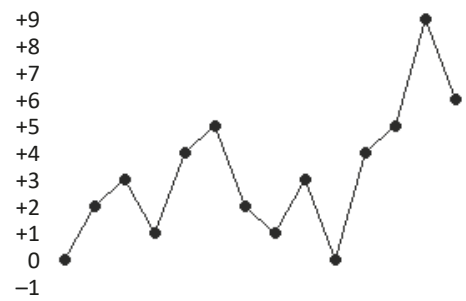

Fig. 6. Step Two - XY Graph Matrix

compaction and anastomosis" [13, p. 102] - with the spirit in which we would approach algebraic formulas. ${ }^{11}$

I have prepared the following ten excerpts for a short paradigmatic analysis through which I hope to show how the Epigraph-Figuration cannot be limited to a singular, unidimensional object. The two-step operation below provides us with the opportunity to observe just how dynamic, asymmetric and plastic the Epigraph-Figuration actually becomes under the composer's hand and throughout his Master and Margarita. These simple steps ${ }^{12}$ involve:

1. a transposition of each excerpt to initiate on concert middle $\mathrm{C}$ and the removal of contiguous pitch redundancies.

2. an XY graph matrix illustrating the melodic contour at its most abstract with "0" equal to the initial pitch; chromatic steps represented by both positive integers (above middle $\mathrm{C}$ ) and negative integers (below middle C) covering more than an octave in both directions; and with each horizontal coordinate point representing the pitches and their direction in the score. Pitch class coordinates then reveal not only the formal upper and lower boundaries of each segmented permutation, but the note-to-note (sequential) pathway by which a bifurcating process is compositionally realized and witnessed by the listener (fig. 4-26).

Variant No. I represents a near perfect, chromatically expanding wedge contour. No pitches are repeated. Four pitches ascend and four pitches descend. There is no corrective

${ }^{11}$ (Authors italics) Melodic contour theory has been rigorously documented - and at the algebraic level - in the analyses of Robert D. Morris in his New Directions of a Theory and Analysis of Musical Contour [14, p. 205-28]. See also [15, p. 232-63].

12 For the sake of brevity I have bypassed the detailing of Step 1 in the following 10 variants. 


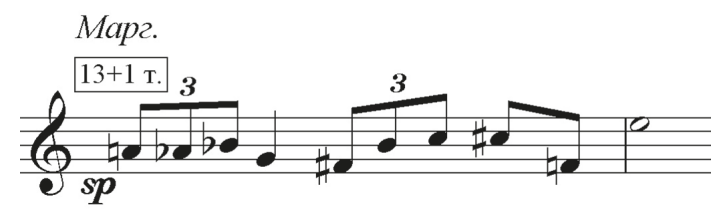

Fig. 7. Variant No. I

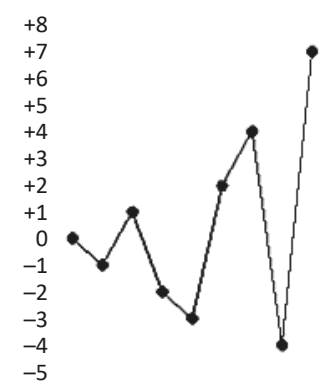

Fig. 8. Graphic Realization of Variant No. I

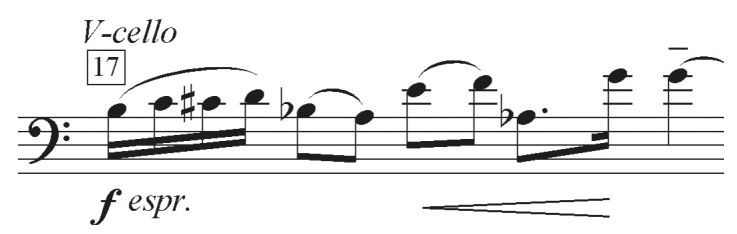

Fig. 9. Variant No. II

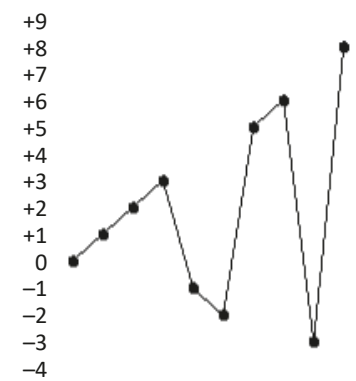

Fig. 10. Graphic Realization of Variant No. II

filling of intervallic space - only an outward dilation from the center. Additionally, three internal pitch coordinates move downwards and, contiguously, three move upwards. This constructive elegance is further accomplished by the three, the initial note contour matching an enlarged version in the final three coordinates.

Variant No. II is as close to a perfect representation of Bruhn's symmetrical model as one finds in these ten excerpts. By drawing a line on each upper and lower trajectory a slightly rough, but clear profile illustrates a wedge-shaped intervallic opening.

Variant No. III begins with a taught clustering of four notes before an upward leap of a major $7^{\text {th }}$, a doubling back on itself which terminates on C-sharp - approximating 


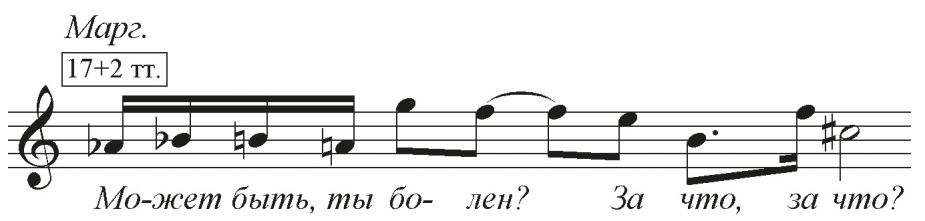

Fig. 11. Variant No. III

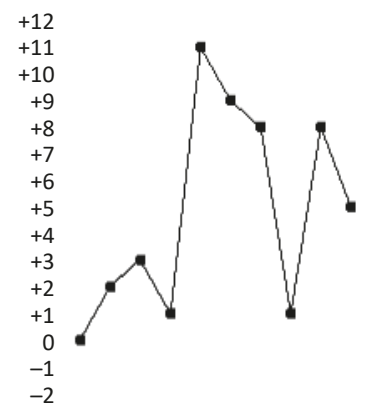

Fig. 12. Graphic Realization of Variant No. III

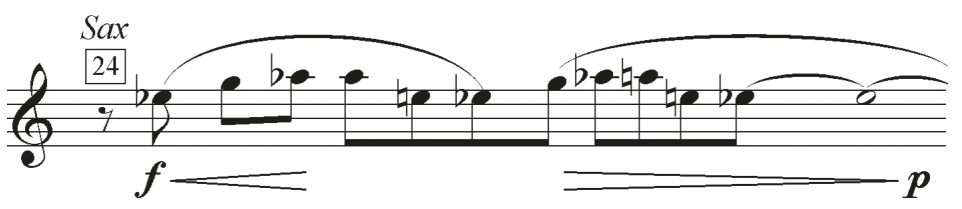

Fig. 13. Variant No IV

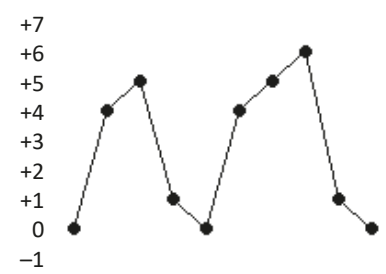

Fig. 14. Graphic Realization of Variant No. IV

the difference between the vertical boundaries. Compromising the expanding wedge paradigm is the lack of a lower pitch boundary descent after the commencing A-flat.

Variant No. IV offers an interesting variant on the expanding wedge as it makes two attempts to push upwards before returning both times to its lowest pitch boundary. What is the semantic take away here - escape, or suppression?

No. V, while far from a symmetrical contour and behaving like a graduated decent, suggests a classic expanding wedge contour with a very dramatic dive of a major $7^{\text {th }}$ to complete its chromatic process.

The first seven notes of Variant No. VI complete a fully chromatic tritone cluster which push out before folding in on itself. This is followed by the remaining 4 notes which commence with two corrective coordinates marking a Perfect $5^{\text {th }}$. "Corrective" because 


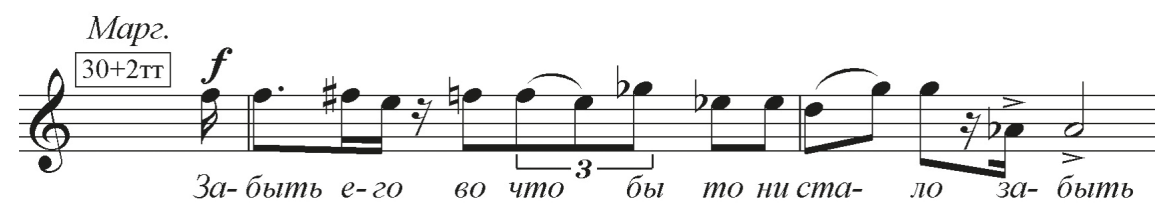

Fig. 15. Variant No. V

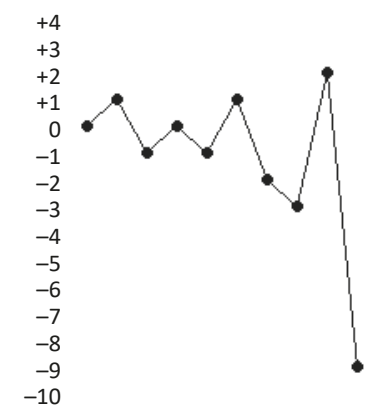

Fig. 16. Graphic Realization of Variant No. V

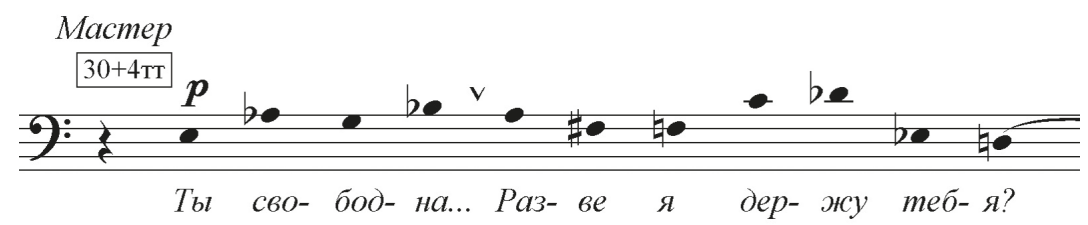

Fig. 17. Variant No. VI

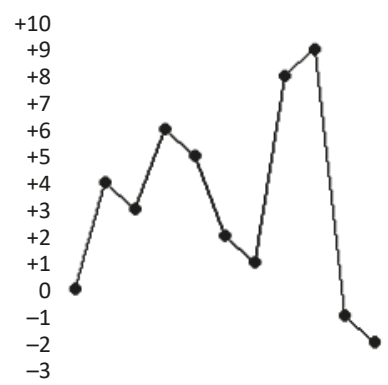

Fig. 18. Graphic Realization of Variant No. VI

in Slonimsky's limpid textures traditional voice-leading proclivities apply: the octave and perfect $5^{\text {th }}$ carry strong psycho-acoustical value and are very audible. It could be argued that Bruhn's "opening" is felt not only by the expanding contour, but also by that perfectly consonant interval following the cluster. However, it is possible as well that this is immediately compromised by the persistence of descending half-steps which follow and progressively orient the ear towards a pitch descent.

Between the initiating F-sharp and C (note 4) a tritone is created in Variant No. VII the interval of which is then, with the exception of two of the remaining twelve notes, 


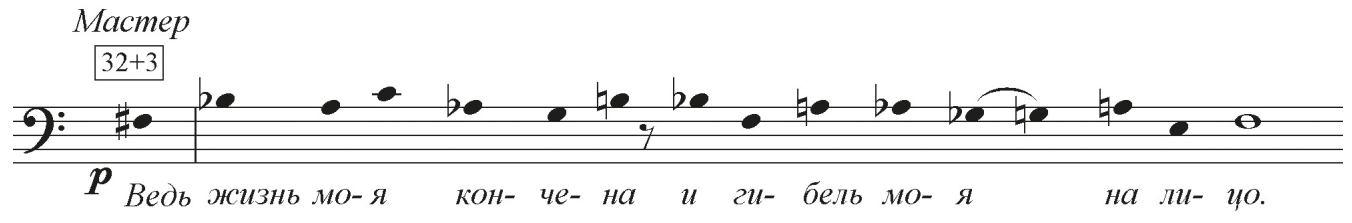

Fig. 19. Variant No. VII

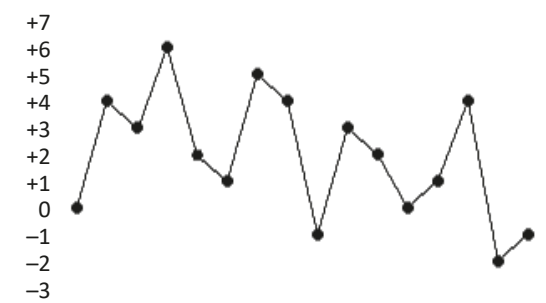

Fig. 20. Graphic Realization of Variant No. VII

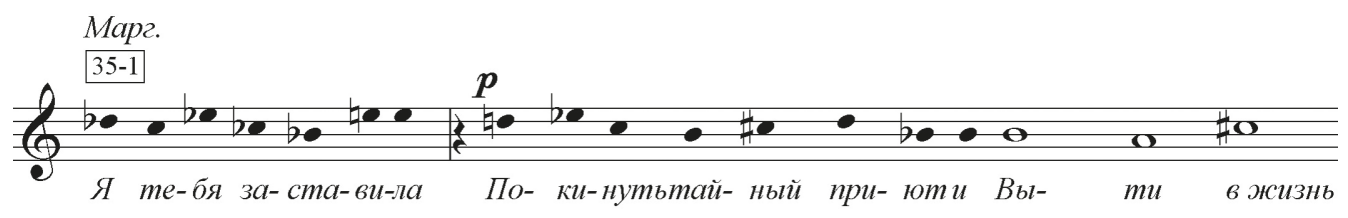

Fig. 21. Variant No. VIII

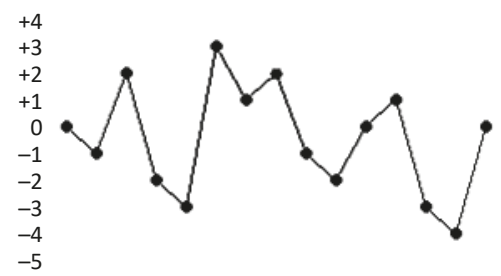

Fig. 22. Graphic Realization of Variant No. VIII

successively extending the lower pitch boundaries, busily filling and refilling that gap. Like no. 3 it can hardly be called a coordinated symmetrical bifurcation. A similar tendency can be read into Variation No. VIII where, with the exception of the penultimate note, A, only the first five of the following fifteen notes chromatically expand the contour leaving the remaining ten to cover the space just opened.

With a preponderance of steps and thirds and a clearly audible sequential imitation immediately following the first five notes, Variant VIII is striking for its more conventionally song-like character than any other example here. There is no clear presence of a defined symmetry.

In Variant No. IX, the fourteen note melody reflects the wedge paradigm more faithfully than the majority of these examples. Three of the first four notes ascend by chromatic steps as well as notes seven and eight. The half-step motion is further mirrored by notes twelve and thirteen on the lower boundary. While not symmetric, the ordinal 


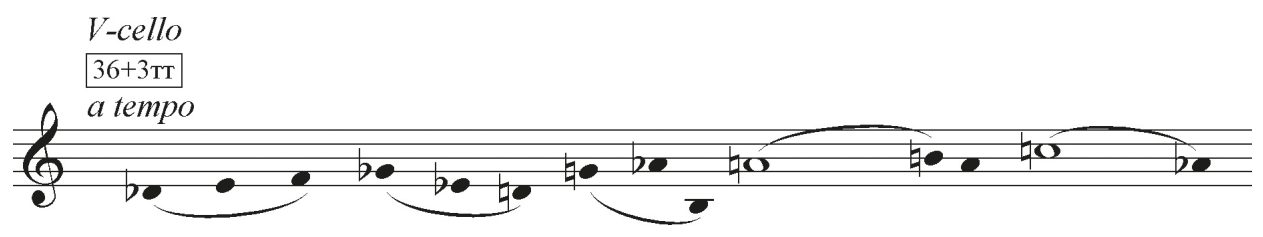

Fig. 23. Variant No. IX

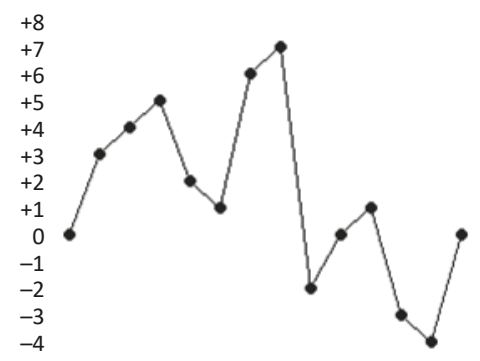

Fig. 24. Graphic Realization of Variant No. IX

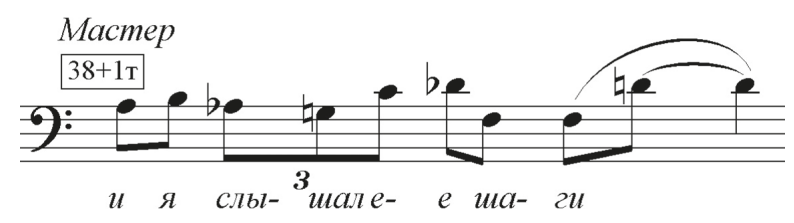

Fig. 25. Variant No. X

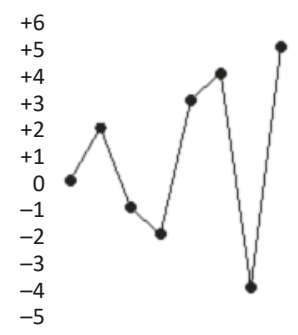

Fig. 26. Graphic Realization of Variant No. X

arrangement of alternating "coordinates" on the vertical axis nevertheless assumes a kind of balance in this contour.

The final example, No. $\mathbf{X}$, comes close to Bruhn's ideal. It is a short and simple wedgeshaped contour with just eight notes - only one of which represents a contiguous repetition.

Lastly to return to the Epigraph-Figuration itself, we can observe how it resembles Variant No. IV in that the lower pitch boundary (and in this case it is synonymous with the initial note) are never transgressed. With its fourteen notes, the defining contour is ultimately one of ascending expansion combined with a series of interlocking pitch coordinates which double back and fill in the pitch space created by the progressive ascending motion of the line. 
The graphs are absent of any overarching objective or recognizable teleology in the dozen variations on the Epigraph-Figuration excerpted for this analysis. In all of the various reincarnations throughout the opera it appears to be detached from any systematic logical development. Instead, it returns over the course of the work in an inexhaustible array of diverse representations - tropes on a single idea ${ }^{13}$ captured by, but not dictated from, the frontispiece epigraph and detailed above. There are important additional contours not examined by Bruhn's hypothesis - just one of which is a progressive tendency towards the opera's conclusion where the initial bifurcation begins to habitually turn in on itself over and over in a kind of "braiding" pattern ${ }^{14}$. Goethe himself asked the important question of how one could possibly compare the clear distinctions of organisms if the very distinctions were themselves constantly changing? [17, p. 153-77]. And, sure enough, in turning over page after page of the score, what is revealed is not one singular melodic topography, but a torrent of kaleidoscopic permutations. Bruhn's article, important as it is, nevertheless favors a reading which excludes the presence of other contours at odds with the idealized expansion model.

But perhaps it is valuable then to recall the words of Jean-Jacques Nattiez - that " $[\mathrm{T}]$ here is no such thing as a totally false theory, there are only theories situated at a certain level of abstraction, and pertinent with respect to one (or more) privileged aspects of musical phenomenon" [18, p. 270]. In this light, sifting through an ocean of literary-musical semiology flowing between Bulgakov's pen and the creative minds of three remarkably disparate composers of the late $20^{\text {th }}$ Century, Bruhn's project is not only legitimatized, but a valuable one in both its novelty and daring intellectual conceit. Bruhn's essay reads like a testimonial of humanist endeavor itself, uncovering the universal threads binding our higher creative selves. The works under her analysis stand for - that is, signal - the hard won battles of the individual artist, either under repressive regimes (Slonimsky, Kunad), or fulfilling a moral duty (Höller) to embolden a stronger awareness of the suffering of the oppressed under such regimes. I think that Bruhn passes over the Epigraph-Figuration too quickly not because she is incapable of recognizing its unique complexity, but both because she has a broader aim in mind and that aim requires a "stepping back from the world and sorting its contents out in discrete entities, [while] the listener in each of us is merging and moving along with a range of its activities" [19, p.21]. To some extent, the present author is guilty of this as well. Through the graphs presented above I have attempted to "freeze" the time-space continuum in an effort to replace, or supersede, one model with numerous others. Factors not considered in this analysis, but inherent to musical phenomena: rhythm, tempo, dynamics, articulation, harmony, polyphony, repetition, the acuity of the listener (intellectual, psychological, physiological), etc. all significantly influence the perception of the very notes we have abstracted here. In this sense the present author is guilty of the same impulse towards ideation — with the caveat that the abstracted models

13 The Epigraph-Figuration lacks a global teleology. It fails to undergo a linear process of developmental transformation, nor as a building block does it merge into the greater fabric of some grand harmonic/ rhythmic plan as is often understood by the term motif. By contrast, York Höller's Der Meister und Margarita which Bruhn includes in her operatic comparisons - was written with a 31-note chromatic "Klanggestalt" (melodic / harmonic design) forming its compositional foundation and commanding the musical syntax on both a local and comprehensive scale throughout the entirety of the opera. See: [16, p. 135].

${ }^{14}$ See Epilogue (p. $357 \mathrm{ff}$. of score) for this in addition to a tendency two-note phrasing structure which favors the famous Slavic "platch" pattern. 
exist only to reveal alternatives to the erroneous implication that figure (figuration, "motif", etc.) follows a limited and unidimensional form.

This is why I prefer to conceive the Epigraph-Figuration as Barratt imagines - an exercise for both composer and listener. Even as a quasi-perceptual compositional element imbedded within the score (and with all of its rhetorical and dramatic activity not under consideration here), the Epigraph-Figuration can train our sensitivity and awareness towards diversity, variation, ingenuity, and the freedom to evolve as the subject chooses to evolve... The possessor of "multiple potentials"15, the Epigraph-Figuration will nevertheless refuse to be easily broken down or reconstituted within some larger formal plan. Courageously charting the course of the libretto's complex dramatic, literary, philosophic and musical complexities, it manages instead to remain true to its singular, yet ever changing, uniqueness throughout. As its melodic contour chromatically expands, twists and turns in on itself in impressively diverse and resourceful ways, one is left with the sense that this Epigraph Figuration is an inexhaustible source of musical generation - a melodic signature particularly fitted to both the harmonic and complex philosophic fabric stretching over Slonimsky's entire composition. Represented by the initial appearance on the opera's frontispiece the Epigraph-Figuration possesses a rank sine qua non and indicates that a course is being set which will mark the progress of the work's musical-dramatic trajectory. A sort of coded tracking device analogous to our quotidian postal deliveries, this insignia announces an "interpretive exercise" encoded as a chromatic melodic series which we may follow throughout Slonimsky's opera. Revealed in the changeable, yet discernible, contour of this figuration is an expertise of compositional handling constitutive of the ontological paradox of morphology itself: recognizability coextensive within a perpetual state of variation. At each new instance it remains its identifiable self. This musical work, from the micro to macro levels, "has a fundamentally ethical [integral] impetus; to pursue a truthful musical mediation of social reality wherever it leads rather than capitulating to something more immediate and entertaining" 16.

\section{Creativity. Growth. Authenticity}

This "truthful mediation" found a concrete and powerful musical form in Slonimsky's Master and Margarita. A historical first in a long line of operatic, balletic, symphonic, music theater, jazz, rock, pop and every other conceivable musical idioms celebrating Bulgakov's novel, the opera was famously shut down by the authorities before the second night of the premiere was underway. The opera ${ }^{17}$ attracted Soviet music culture's elite and packed its audience tightly into the performance hall of the Leningrad Composers Union with both opera and the events surrounding it drawing comparison with Bulgakov's dys-

15 See: [20, p.46]. Morson and Emerson characterize Bakhtin's concepts of "Unfinalizability" and "Historicity" in the following way: "In short, biological structures, like social entities, are at once designed, undersigned, and ill-designed - they change in an imperfect way, and they give rise to by-products. For all these reasons they exhibit the potential for the unforeseen". The fortuitous collision of literary-musical elements which saturate the semiotic space of Bulgakov's Master and Margarita have helped to create an explosion of creativity engendered by the novel, suggesting that, to twist Woland's words, Manuscripts don't burn - they simply proliferate...

${ }^{16}$ Or for that matter, to likewise overextend towards the grandiose, cerebral, extramusical, I would add. See [9, p. 104].

17 Premiered April 10, 1972. The production, conducted by Gennady Rozhdyetsvensky, included Act I only. 
topian and authoritarian state. This untimely closing of Master and Margarita with its obvious irony of life imitating art was just one more instance over a remarkably long creative career which the level-minded Slonimsky shrugged off with his usual detachment.

It is easy to see how it was said that Slonimsky "simply could not not write [Master and Margarita]" [21, p. 164] and no one understood this better than his pupils. Pity the poor student who did not quickly learn that Sergei Mikhailovich was unable to endure personal laziness nor the type of unreflective allegiance that would accompany popular aesthetic trends. This was constantly reaffirmed as he counseled young composers to develop their own voice, musical prerogatives and strategies, and by no means limit themselves to any one singular stylistic direction - whether fashionable or long obsolete. When Slonimsky sensed there was a real talent he would then encourage the pursuit of maximum artistic freedom and expression, but his criticism could be withering. In an interview taken as recent as November $2019^{18}$, he would emphasize repeatedly and explicitly that his Jeshua, his opera, was "diametrically opposed to the concept of Jesus Christ Superstar". The concern for stardom, or glamour of any kind, was never anywhere near Slonimsky's orbit of creativity. He simply followed an organic, subjective creativity without regard to public criticism. Drawing a comparison with Bulgakov's Master and Margarita he found it "strange that he [Master] couldn't overcome the feeling of victimization by his critics. By contrast, take me for example", he elaborated in the interview, "I've had to listen to those kind of critics 20,000 times! [And] It never changed a thing".

Lastly, the teacher Slonimsky possessed a tremendous reserve of generosity which did not always square with the outwardly prickly and restive nature of his classroom persona. Indeed, in many ways he embodied the antithesis of Bulgakov's celebrated, avoidant-proned and broken Master. That writer, we will remember, was prepared to abdicate responsibility for his grand opus - which he tried to destroy - in exchange for comfort, rest, and anonymity. The last thing that could interest Slonimsky, himself the son of a distinguished writer, was a retreat from one's cultural responsibility to produce. On the contrary, Slonimsky's blustery, creative presence and bold, formidable intellect would better suit a comparison with the much more celebrated (ultimately more beloved and awesome) male protagonist of Bulgakov's Master and Margarita - the sardonic maker of destinies and the emancipator from oblivion, Monsieur Woland ${ }^{19}$. It therefore could not possibly be more ironic that in 1972 the Leningrad Party Committee should have banned the radio recording release of the opera's premiere, having "determined" that the composer Slonimsky had attempted to draw a parallel between himself [22, p. 138] and the pitied and fear-filled Master.

Earlier in 2018 St. Petersburg publishing house, Kompozitor, released Melody - Sergei Slonimsky's definitive text on the theoretical subject closest to the composer's heart and the culmination of a life's expertise and research. The 400-page analysis casts its wide net over a sea of melodic history, embracing the ancient monodic systems, Russian folkloric and national idioms, $19^{\text {th }}$ Century styles and beyond to the work of Ives, Webern even Boulez and Ferneyhough. In the introduction the author writes ${ }^{20}$ :

18 Interview 13.11.2019. The home of Sergei Slonimsky. St. Petersburg, Russia.

19 In the November 2019 interview Slonimsky was quick to point out that, despite an indisputable element 35 of satanism in the novel, Woland's characteristic behavior is, for the most part, morally on the side of Good. "He enacts evil only upon those who are unrepentingly dishonest".

20 Author's italics. 
"But why does [melody] shape itself into an inimitable, musical idea - an unforgettable form - remains unclear" $[23$, p. 12].

In conclusion I would like to suggest that Slonimsky's Epigraph-Figuration, an intertextual melodic abstraction, an "unforgettable form" and an invention of his that he felt worthy of countless repetition, nevertheless seems perfectly tailored to the particular issues of good and evil at the heart of Bulgakov's novel. Slonimsky's own life gave concrete human form to the paradigm of plasticity and courageous resilience that makes the Epigraph-Figuration itself such a universally affecting power. So what better way to approach a clarification of the problems of meaning for this elusive, constantly unfolding and fluid, "inimitable" morphology, and "unforgettable form" of the Master and Margarita's Epigraph-Figuration than by an appeal to the author of the original epigraph - Johann Wolfgang von Goethe? Goethe's own obsessive observation of life forms ${ }^{21}$ grew out of a desire to understand the very same continuous unfolding variation of organic, permutational growth - not entirely unlike Slonimsky's taxonomy of the multiplex of variation, the "proliferous carnation" [13, p. 95] — that we call melody...

"Gender can become species, the species a variety, and these can mutate to infinity through other conditions"

Johann Wolfgang Goethe, Schriften zur Morphologie (1817)

\section{References}

1. Barratt, Andrew. "Beyond Parody: The Goethe Connection". In The Master and Margarita: A Critical Companion, ed. by Laura D. Weeks, 131-21. Evanston: Northwestern University Press, 1996.

2. Bulgakov, Mikhail. The Master and Margarita. Transl. by Hugh Alpin. London: Alma Classics, 2008.

3. Baldick, Chris. "Epigraph". In Baldick, Chris. The Oxford Dictionary of Literary Terms. ${ }^{\text {th }}$ ed. Oxford: Oxford University Press, 2015. Accessed January 20, 2020. https://www.oxfordreference.com/ view/10.1093/acref/9780198715443.001.0001/acref-9780198715443-e-396? rskey=6n3C3j\&result $=402$.

4. Gosudarstvennyi institut iskusstvoznaniia, Moskovskaia gosudarstvennaia konservatoriia im. P. I. Chaikovskogo. A Theory of Modern Composition. Ed. by. Valeriia Tsenova. Moscow: Muzyka Publ., 2005. (Academia XXI: uchebniki i uchebnye posobiia po kul'ture i iskusstvu). (In Russian)

5. Milka, Anatoly. Sergei Slonimsky: Monographic Essay. Leningrad; Moscow: Sovietskii kompozitor Publ., 1976. (In Russian)

6. Lotman, Yuri M. Universe of the Mind: A Semiotic Theory of Culture. Introd. by Umberto Eco, transl. by Ann Shukman. Bloomington: Indiana University Press, 2001.

7. Rizarev, Marina G. Composer Sergei Slonimsky: Monograph. Leningrad: Sovietskii kompozitor Publ., 1991. (In Russian)

8. Bruhn, Siglund. "Jesus and Satan in Moscow: Three Late- $20^{\text {th }}$ Century Operas on Bulgakov's Novel". Journal of Music and Meaning 4 (2007). Accessed January 20, 2020. http://www.musicandmeaning.net/ issues/showArticle.php?artID=4.2.

9. Johnson, Julian. Who Needs Classical Music? Cultural Choice and Musical Value. Oxford: Oxford University Press, 2002.

10. The New Grove Dictionary of Music and Musicians, s. v. "Motif" by William Drabkin. Accessed January 20, 2020. doi: 10.1093/gmo/9781561592630.article.19221.

21 "Here it is crucial that we thoroughly observe and compare the different stages nature goes through in the formation of genera, species, and varieties, as well as in the growth of each individual plant" [13, p. 102]. 
11. Rudnev, Vadim. Dictionary of $20^{\text {th }}$ Century Culture: Key Concepts and Texts. Moscow: Agraf Publ., 2001. (In Russian)

12. Cross, Jonathan. Harrison Birtwistle: Man, Mind, Music. Ithaca, N. Y.: Cornell University Press, 2000.

13. Goethe, Johann Wolfgang. The Metamorphosis of Plants. Introd. by Gordon L. Miller, transl. by Douglas Miller. Cambridge, MA: MIT Press, 2009.

14. Morris, Robert. "New Directions of a Theory and Analysis of Musical Contour". Music Theory Spectrum 15, no. 2 (1993): 205-28. doi: 10.2307/745814.

15. Quinn, Ian. "Fuzzy Extensions to the Theory of Contour". Music Theory Spectrum 19, no. 2 (1997): 232-63. doi: 10.2307/745755.

16. Dunne, Timothy. "Gestaltkomposition of York Holler: The Opera 'Master and Margarita' and their Humanitarian Foundation". Opera musicologica, no. 3-4 (2011): 135-50. (In Russian)

17. Wellmon, Chad. "Goethe's Morphology of Knowledge, or the Overgrowth of Nomenclature". Goethe Yearbook 17 (2010): 153-77. doi: 10.1353/gyr.0.0075.

18. Nattiez, Jean-Jacques. Music and Discourse: Toward a Semiology of Music. Transl. by Carolyn Abbate. Princeton, N. J.: Princeton University Press, 1990.

19. Burrows, David. Sound, Speech, and Music. Amherst, MA: University of Massachusetts Press, 1990.

20. Morson, Gary Saul, and Caryl Emerson. Mikhail Bakhtin: Creation of a Prosaics. Stanford Calif.: Stanford University Press, 1990.

21. Gosudarstvennyi institut iskusstvoznaniia, Nizhegorodskaia gosudarstvennaia konservatoriia im. M. I. Glinki. History of National Music in the Latter Half of the $20^{\text {th }}$ Century. Ed. by Tamara Levaia. St. Petersburg: Kompozitor Publ., 2005. (Academia XXI: uchebniki i uchebnye posobiia po kul'ture i iskusstvu). (In Russian)

22. Ritzarev, Marina G. "From the Cathedral to the Opera Stage". Vestnik of Saint Petersburg University. Arts 7, no. 2 (2017): 132-43. doi: 10.21638/11701/spbu15.2017.201.

23. Slonimsky, Sergei. Melody. St. Petersburg: Kompozitor Publ., 2018. (In Russian)

\section{Music Editions}

I. Slonimsky, Sergei. Master and Margarita: Chamber Opera. Score. St. Petersburg: Kompozitor Publ., 2004. (In Russian)

Author's information:

Timothy Andrew Dunne - Dr. Habil.; dunne.timothy@gmail.com 